Revista de la red interuniversitaria de estudios sobre las literaturas rioplatenses contemporáneas en Francia

17 | 2017

Hermetismo programático en la literatura rioplatense contemporánea (de 1980 a nuestros días)

\title{
De la ciega taquigrafía: la elusiva erudición de Luis Chitarroni
}

Julio Prieto

\section{OpenEdition}

1 Journals

Electronic version

URL: http://journals.openedition.org/lirico/3807

DOI: 10.4000/lirico.3807

ISSN: 2262-8339

Publisher

Réseau interuniversitaire d'étude des littératures contemporaines du Río de la Plata

\section{Electronic reference}

Julio Prieto, « De la ciega taquigrafía: la elusiva erudición de Luis Chitarroni », Cuadernos LIRICO [En línea], 17 | 2017, Puesto en línea el 17 diciembre 2017, consultado el 02 mayo 2019. URL : http:// journals.openedition.org/lirico/3807; DOI : 10.4000/lirico.3807

This text was automatically generated on 2 May 2019.

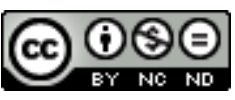

Cuadernos LIRICO está distribuido bajo una Licencia Creative Commons Atribución-NoComercialSinDerivar 4.0 Internacional. 


\title{
De la ciega taquigrafía: la elusiva erudición de Luis Chitarroni
}

\author{
Julio Prieto
}

En una nota sobre el poeta y crítico británico William Empson, Luis Chitarroni encomia la « fogosa erudición » del autor de Siete tipos de ambigüedad (1930) y Estructura de las palabras complejas (1951). ${ }^{1}$ El elogio se asocia a un cierto ejercicio de la oscuridad que el autor argentino en gran medida toma como modelo de su propia práctica -Chitarroni describe a Empson como una especie de "Rembrandt de la crítica literaria ", ${ }^{2}$ lo que bien podría aplicarse a su propia escritura. En este ensayo quisiera explorar una cualidad de erudición emparentada con ese ejercicio: lo que podríamos llamar una erudición reticente, una suerte de modo "infraleve» de la erudición - "trazo breve, veloz tachadura, ciega taquigrafía », como sugiere un pasaje de su « novela inconclusa » Peripecias del no. ${ }^{3}$ Modo estrechamente ligado a la poética de la opacidad y al específico juego de oscuridades y destellos que trabaja la escritura de Chitarroni -algo que también se podría describir, en los términos que elige para caracterizar a Empson, como el deslinde de « una zona de exclusión, el contorno de una oscuridad ». ${ }^{4}$ En el rastreo de esa "zona » es importante tener en cuenta otro rasgo de estilo admirado en Empson: su uso de la lítote (es decir, la figura consistente en decir lo que no es, en lugar de afirmar que algo es). En otras palabras, cierto modo de decir atenuado, de nombrar denegando, según propone el título de su antinovela Peripecias del no, así como el de una de las numerosas obras virtuales citadas en ella (un supuesto ensayo acerca de una revista literaria apócrifa): « Nombradía, polinomia y denegación en Ágrafa ». ${ }^{5}$

2 Mi lectura se orientará a triangular estas erudiciones oscuras o "denegantes » con el modo de erudición legible (si bien frecuentemente abismal) que propone la literatura de Borges, punto de fuga ineludible en la literatura argentina contemporánea, que en gran medida es posible describir como una densa trama de líneas " contraborgianas ». ${ }^{6}$ En esa trama, la escritura de Chitarroni tiene un papel destacado junto a las productivas ilegibilidades ensayadas por autores como Fogwill, Laiseca, Aira, Chejfec, Guebel, Cucurto o Bejerman, entre otros: autores que imaginan diversas formas de « aplacar los excesos de sentido de la literatura ", según propone Chitarroni en la nota sobre Epson ${ }^{7}$, y que 
podemos ubicar en la estela de una larga saga de errancias y poéticas de lo ilegible rioplatenses -desde Macedonio Fernández, Roberto Arlt o Felisberto Hernández a los hermanos Lamborghini, Copi, Perlongher, Pizarnik, Zelarrayán o Libertella. ${ }^{8}$ El principio de exploración de mi lectura, focalizada en Peripecias del no, será entonces el verso de Dylan Thomas evocado por Chitarroni en esa nota (así como en la «novela inconclusa »): "La oscuridad es un camino y la luz un lugar $»{ }^{9}$

Peripecias del no. Diario de una novela inconclusa, tercera novela de Chitarroni -tras El carapálida (1997) y Miopía progresiva (2001)-, empieza así:

LOS NOMBRES son los que están desde 1986 o antes (nota bochornosa en no me acuerdo qué publicación, el grupo Shanghai). Nicasio Urlihrt, Hilarión Curtis, anagramas. Oliverio Lester, Inés Máspero, Cora Estrugamou.

Nombres pesados, pero menos que en El carapálida. Contra el segundo Calvino, todo debe carecer de liviandad. (2007: 7)

En este comienzo llaman la atención varias cosas: primero, la consigna beligerante esgrimida contra una figura canónica de la literatura de finales del siglo XX (Italo Calvino); segundo, la reivindicación de una cierta densidad literaria -un "peso » que se opondría a la «liviandad» que, de acuerdo con la predicción de Calvino en sus Seis propuestas para el nuevo milenio (1985), habría de ser el rasgo preeminente en la literatura del siglo XXI-; tercero, el énfasis en "LOS NOMBRES»-palabras que se destacan con letras mayúsculas y que introducen uno de los motivos centrales la novela: lo que podríamos llamar el tema de la «nominación insidiosa », toda vez que la lista de nombres que aparece tras la frase inicial plantea una notable ambigüedad en cuanto a su estatuto histórico o ficticio. El hecho de que dos de esos nombres -Nicasio Urlihrt, Hilarión Curtisse identifiquen como "anagramas» despierta ya nuestras sospechas, pero sigamos leyendo un poco más antes de detenernos en ellas:

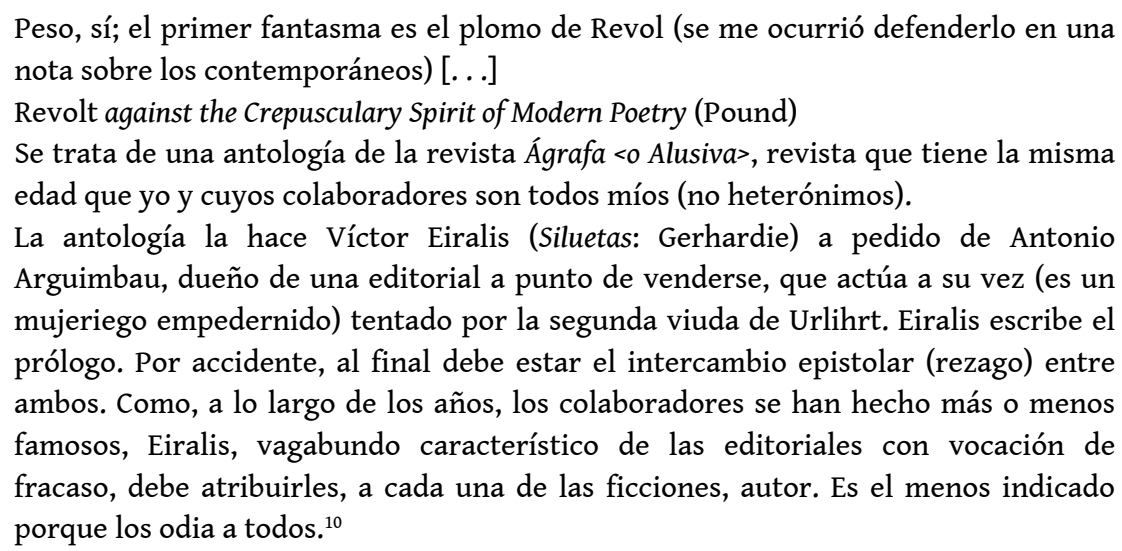

5 Hasta aquí la primera página de la novela, que da la nota dominante en las doscientas y pico que siguen: una notable opacidad atravesada por "destellos informativos " $^{11}$, fragmentos de una historia que no acaba de hacerse visible, una suerte de avance a base de fogonazos a través de una frondosa acumulación de enigmas y referencias inciertas que simultáneamente invitan y rechazan la interpretación -nominaciones indefinidas que ponen en juego una específica dinámica de iluminación y ceguera, una suerte de parpadeo entre el deseo y la futilidad de leer.

6 Esta hermética obertura está recorrida por un inconfundible aire borgiano: notoriamente lo evocan la puesta en juego de un gesto de erudición ostentosa (que no excluye la alusión explícita o apenas disimulada a la propia obra), la propuesta de acertijos detectivescos y el trabajo con una suerte de ambivalencia endémica entre lo real y lo ficticio, un 
específico gusto por las paradojas de lo apócrifo que remite al programa que propone Borges a través de su alter ego Pierre Menard: « la técnica del anacronismo deliberado y de las atribuciones erróneas $»{ }^{12} \mathrm{Si}$ nos fijamos sólo en los nombres propios que proliferan en esta primera página, podemos identificar una serie de figuras y escenas de la historia literaria reciente: el " grupo Shanghai ", término con el que suele aludirse al grupo de escritores nucleado en torno a la revista Babel (1988-1991), integrado por el propio Chitarroni y por una serie de autores argentinos hoy bastante notorios, como no deja de señalarlo el pasaje citado -Alan Pauls, Sergio Chejfec, Sergio Bizzio, Daniel Guebel, Charlie Feiling, Matilde Sánchez y Martín Caparrós, entre otros. ${ }^{13}$ Pero estas figuras y otras de historicidad manifiesta, como Ezra Pound o "el segundo Calvino» (ya se aluda a la segunda etapa del escritor Italo Calvino, o a ese mismo autor en cuanto segundo "Calvino" relevante en la Historia después del teólogo reformista del siglo XVI), se mezclan con otras de historicidad mitigada cuando no francamente dudosa. Así, las tres obras que se mencionan son obras reales de dos autores históricos: Siluetas es un libro de Chitarroni (una colección de retratos de escritores, originalmente publicados en la citada revista Babel), al igual que El carapálida (su primera novela); y la obra aludida de Pound es un poema de juventud del autor de los Cantos (si bien por la manera en que se lo cita, poniendo el título en bastardillas, podría pensarse que se trata más bien de un libro o de un ensayo). ${ }^{14}$ Podemos, incluso, extremando el ejercicio hermenéutico, identificar otra figura histórica cifrada en los nombres « Nicasio Urlihrt, Hilarión Curtis »-que de hecho son exactos anagramas del nombre del autor: Luis Chitarroni. Pero ¿qué decir de la lista de nombres que lo acompañan? ¿Habría que ver en Oliverio Lester, Inés Máspero, Cora Estrugamou, otros tantos nombres en clave de los autores que integraron con Chitarroni el grupo Shanghai? $¿ \mathrm{O}$ son invenciones sin mayor voluntad de correspondencia cifrada con esos u otros escritores? ¿Es la revista Ágrafa (o Alusiva) un trasunto ficticio de la revista Babel o quizá de la revista Literal (o de ambas, como propone Pedro B. Rey en la reseña que apareció en La Nación) $?^{15}$ ¿Es de hecho una « revista », habida cuenta de que el autor afirma que "todos sus colaboradores son míos»? ¿Son todas las colaboraciones de esa revista obras (reales o imaginarias) del autor de la novela, o son todos sus « colaboradores » criaturas ficticias, siluetas imaginadas por él a partir de modelos más o menos históricos? Aunque esta cuestión nunca llega a aclararse del todo, el desarrollo de la novela parece inclinarse hacia la primera hipótesis, ya que la antología de artículos de esa « revista ", cuya intrahistoria es uno de los tenues hilos narrativos que propone esta "novela inconclusa », pronto muta en una colección de relatos y borradores de relatos del propio Chitarroni -obras "reales» en el sentido de anteriormente escritas y en algunos casos publicadas por este autor (como es el caso de "Temprano ") a la vez que semi-ficcionales en el sentido de estar siendo reescritas en el proceso de composición de este texto y de estar íntimamente ligadas a su pseudo-narrativa « peripecia ». Lo que, en una suerte de bucle de Moebius, nos devolvería a la segunda hipótesis: la semificcionalidad (a la vez que semi-historicidad) de sus « colaboradores » en cuanto figuras intermitentemente históricas, re-creadas en la escritura de este texto más allá de su elusivo anclaje en una realidad comprobable ${ }^{16}$-por eso los «colaboradores» de Ágrafa serían " suyos », sin ser exactamente " heterónimos » (aun cuando varios de los nombres autoriales que proliferan en el texto de hecho funcionen como tales). ${ }^{17}$

$7 \quad$ ¿Y qué decir de los nombres Revol, Víctor Eiralis y Gerhardie, respectivamente vinculados al poeta Ezra Pound, a un libro de Chitarroni -Siluetas- y a la hipotética Ágrafa/Alusiva? Revol -que leído al revés da «lover» y se presta al juego de palabras (revolt, volver, revólver), como lo evidencia el calambur interlingüistico inserto en el título del poema de 
Pound («Revol/Revolt against the crepuscular spirit of modern poetry »)- y el bizarro y poco verosímil Gerhardie parecerían tener todos los boletos para ser apócrifos. ${ }^{18}$ Sin embargo, una somera pesquisa bibliográfica pronto nos aclara que Revol es Enrique Luis Revol, profesor cordobés de literatura inglesa y autor de la novela Mutaciones bruscas (1971), oscura obra elogiada por Chitarroni - « pedante y deliciosa », la llama en una entrevista ${ }^{19}$ -, y del que se dice que se carteó con Thomas Pynchon -quien se habría basado en sus informaciones para componer la sección sobre Argentina y los gauchos de Gravity's Rainbow. ${ }^{20} \mathrm{Y}$ la consulta del volumen Siluetas nos revela que Gerhardie es William Alexander Gerhardie, improbable pero de hecho histórico escritor de culto ruso, autor políglota y expatriado en Londres, al que Chitarroni compara ventajosamente con Nabokov -« [sus libros] son mejores [...], más puros en su mezcla »-21 y cuyas excéntricas novelas -Los políglotas (1925), Hecatombe (1928)- han sido recientemente recuperadas por la editorial española Impedimenta.

8 En cuanto a Víctor Eiralis, personaje que en efecto aparece en la nota de Siluetas sobre Gerhardie y que tiene cierto protagonismo en Peripecias del no como compilador de la antología de Ágrafa/Alusiva, todo parece indicar que es una invención de Chitarroni, o incluso una suerte de trasunto autorial grotesco. De hecho la acrimonia de la relación entre Eiralis y el personaje-narrador "Chitarroni ", marcada tanto en la nota de Siluetas como en Peripecias del no por el rencor y los celos literarios, sugiere una reescritura paródica de «El Aleph» de Borges. La histriónica hostilidad entre Eiralis y Chitarroni recuerda la acerba a la par que desternillante relación entre el personaje-narrador " Borges » y el fatuo plumífero Carlos Argentino Daneri, que en ese relato funciona como doble siniestro del autor (un suerte de reflejo deforme de la figura autorial que construyen las ficciones borgianas). En la fulminante sentenciosidad de Eiralis retornan los pedantes dictámenes de Daneri, si acaso sensiblemente mejorados en su coruscante e hiriente maledicencia. Daneri dice: « La verdad no penetra en un entendimiento rebelde » o «Claro está que si no lo ves [el aleph], tu incapacidad no invalida mi testimonio »22; Eiralis dice: «Soñé que usted era inteligente y que yo no había tenido la desdicha de conocerlo ». ${ }^{23}$ Daneri dice: «Bufas, mi lamentable amigo, de envidia, pero confesarás aunque te ahogue- que esta vez pude coronar mi bonete con la más roja de las plumas " ${ }^{24}$; Eiralis dice: « Le conviene empezar a fracasar antes de que el error le haga creer que tuvo éxito $»^{25} \mathrm{o}$ : « ¿Usted escribe así de mal de corrido o las partes que están pésimo las pasa a limpio? $»{ }^{26}$

9 Ahora bien, así como en la primera página de Peripecias del no podemos observar una serie de notorios gestos y tics borgianos, no es menos ostensible la exacerbación de esos gestos, llevados hasta un punto extremo en el que su eficacia se pierde en una suerte de efecto de derrape o colapso chirriante. A la vez, podemos constatar algunos rasgos muy poco borgianos: entre otros, el gusto por el retruécano y los juegos lingüísticos, que remiten más bien al gusto de un Joyce o un Cabrera Infante por las palabras portmanteau o a los alardes y proezas del ingenio barroco tan denostados por la economía de la dicción clásica de Borges -denostados en la medida en que en su relato autobiográfico del estilo representan una afección juvenil, que padeció en sus inicios como escritor y que habría sido felizmente superada en su obra de madurez..$^{27}$ "Burdel de palabras cruzadas ", ${ }^{28}$ llama Chitarroni a este « diario de novela inconclusa $»^{29}$, descripción justa a la luz de los promiscuos acoplamientos lingüísticos (amén de intertextuales y genéricos) que fomenta. Enumero algunos: «Revol/Revolt», «Cleptolalia/Criptodermia» (y viceversa: «Criptolalia/Cleptodermia »), «Urlihrt/ Nurlihrt», «Edición/sedición », 
«Epilogoliponema », « Idiomatías », " Cimétrica Sircular » (jugando con la homofonía de la $\mathrm{C}$ y la S seguidas de vocal cerrada en el español americano, lo que por cierto introduce un tema de "simetría paródica» que recorre no sólo esta novela sino una serie de escrituras contemporáneas « contraborgianas $»^{30}$ ), por no mencionar la vena neologística de la co-fundadora de Ágrafa, Elena Siesta (verbigracia: caminancia, dosdichas, freakativa, lepro- $y$ letrorrea, oligoría, ombligopaedia, pangustia, titubeosis...). ${ }^{31}$ En la misma categoría cabría incluir el par "peso/Pound", a partir del doble sentido de " pound ", que además de ser el apellido de un famoso poeta es una medida de peso inglesa, lo que nos llevaría a preguntarnos si la « revuelta » que promueven Revol y los otros autores confabulados en este crepuscular comienzo sería contra la liviandad de Calvino o más bien contra « el peso de Pound $»-o$ el de Borges, pues todo en este texto apunta a que la revuelta orquestada por su autor y su coro de díscolos secuaces (más o menos históricos o ficticios) va ligada a un enfrentamiento con la figura de éste. ${ }^{32}$

El gesto de la erudición excesiva obviamente remite a la práctica literaria de Borges, pero en cierto modo es como si ese gesto y esa práctica hubieran sido sometidos a la operación de « tajeamiento » que pone en práctica la escritura neobarroca de Osvaldo Lamborghini. ${ }^{33}$ Es como si por una suerte de monstruosa mutación (algo así como lo que acontece en la película La mosca), «Pierre Menard" se hubiera hibridado con El Fiord. Algo del deslizamiento (neo)lingüístico y el destrenzamiento textual de Lamborghini (algo: quizá una pata o una cabeza de mosca) hay en la tendencia al espaciamiento ostensible en Peripecias del no, cuya prosa frecuentemente deriva hacia una verticalidad donde los bloques narrativos se deshilachan en listas de nombres y espacios en blanco que adquieren fugaces cualidades poemáticas. A menudo el relato «taquigráfico » se disuelve en listas heteróclitas de nombres "denegantes", ráfagas de referencias literarias y (auto)biográficas truncas - « suites de nombres $»^{34}$ alusivos-elusivos que pueden leerse como poemas concretos y que ponen en juego un específico " espaciamento de la lectura » (en el sentido mallarmeano del término). ${ }^{35}$ Es que en la escritura « taquigráfica » lo que en cierto modo está en juego es producir algo que estaría entre la prosa y la poesía (o más allá de ambas) -una "música a la deriva ${ }^{36}$ como se sugiere a partir de una cita de Pessoa: "'Para los sentimientos vagos, que no admiten definición, existe un arte, la música, cuyo fin es sugerir sin determinar. Para los sentimientos perfectamente definidos, de tal modo que la emoción es difícil en ellos, existe la prosa. Para los sentimientos que son armónicos y fluidos, existe la poesía' ». ${ }^{37}$ La escritura " denegante ", vale decir, sería una práctica que se aproximaría a la música en cuanto arte de « sugerir sin determinar» -pero no en el sentido de la musicalidad de la poesía simbolista rechazada por Pessoa (y presumiblemente por Chitarroni) sino más bien como una suerte de música aleatoria, como producción de un « espacio de indeterminación ».38

11 A la erudición borgiana, que propone incontables pistas a seguir en un marco de estabilidad narrativa que cultiva el placer del relato -lo que en términos de Chitarroni llamaríamos un "régimen narrativo aticista en equilibrio " $^{39}-$, se opondría la erudición aleatoria o abstracta de Peripecias del no -una suerte de erudición «sin profundidad de campo ", que problematiza la visión del cuadro en términos de perspectiva clásica (ilusión que los relatos de Borges tienden a fomentar y mantener hasta llegar a un determinado punto de fuga o cegamiento vertiginoso). Aunque la «novela inconclusa » de Chitarroni propone un juego de desciframiento detectivesco comparable a los que plantean muchos de los relatos de Borges, siempre se llega a un punto en que el juego hermeneútico se frustra, expulsándonos del texto y del relato, o bien la proliferación de enigmas y 
oscuridades se multiplica hasta tal punto que la perspectiva de algún tipo de elucidación se difiere hasta el infinito. ${ }^{40}$ Como se dice de uno de los virtuales textos de Ágrafa - «La misa en lenguas "-, " hay que compartir una serie tan grande de sobreentendidos que cualquier lector normal pierde antes la curiosidad y la paciencia $\Perp^{41}$ Es que, como lo sugiere otra de las presuntas colaboraciones de Ágrafa, este texto pone en juego una estrategia de «polinomia y denegación » que concibe la (anti)novela como «bosque de nombradías desiguales »:

Onomástica, nombradía, polinomia y denegación en Ágrafa. [...]

Al revés de lo pedido por Ockham, las entidades nominativas de Ágrafa nacen para proliferar, reproducirse, ser abandonadas. Son lo que son apenas o acaso por énfasis de contraste, carraspera, catarro. [...] Los nombres funcionan como categorías algebraicas sin relación con el resultado final. Se acumulan, se coleccionan, se gastan (en doble acepción). La metástasis vive en ese bosque de nombradías desiguales. ${ }^{42}$

Puestos a cotejar erudiciones y oscuridades, la diferencia entre Borges y Chitarroni vendría a ser como la diferencia entre Góngora y Lezama. Si en Borges y en Góngora se propone un juego de enigmas que construye relato y apunta a una desciframiento final (por más que ese juego conduzca en Borges a desenlaces vertiginosos que revelan la imposibilidad o futilidad del desciframiento, y en Góngora se complique tanto que se pierde de vista la salida del laberinto), en Chitarroni, como en Lezama y en general en la poesía neobarroca, se tiende a la pérdida del relato y a un indefinido diferimiento del sentido. ${ }^{43}$ Como lo sugieren metapoéticamente varios de los títulos de obras virtuales que recurren a lo largo del texto -Las equis distantes; Efectos de la demora, reflejos de la distancia${ }^{44}$, las incógnitas en este libro se distancian o se difieren, raramente se resuelven.

La estrategia de proliferación de nombres "sin relación con el resultado final ", así como de líneas narrativas que continuamente se interrumpen, reproduciéndose en una suerte de «metástasis » descontrolada en nuevas trayectorias de denegación y diferimiento, recuerda no sólo la práctica de diseminación semiótica de las poéticas neobarrocas latinoamericanas sino también la estructura narrativa de una novela como La perla del emperador (1990) de Daniel Guebel (integrante como Chitarroni del grupo Shanghai) así como de muchas novelitas de Aira, autores que habría que incluir en la órbita de las conspiraciones « contraborgianas ». « Al revés de lo pedido por Ockham » (y cabe agregar: al revés de lo propugnado por la poética de la ficción borgiana, que de acuerdo con el principio de la «navaja de Ockham» aborrece la multiplicación de entidades innecesarias) estos autores promueven distintas estrategias de gasto semiótico y narrativo -si bien diríamos que, en el espectro " contraborgiano », Chitarroni estaría en un punto intermedio entre el extremo de ilegibilidad de un Lamborghini o un Perlongher y los decididamente menos oscuros Aira y Guebel, aun cuando sus textos tematicen a menudo la ilegibilidad. ${ }^{45}$

Acorde con la vocación revoltosa de esta constelación " contraborgiana ", en Peripecias del no abundan las versiones paródicas de la literatura de Borges - $\mathrm{o}$, como socarrona y anagramáticamente se lo invoca en cierto punto, de «ese árbitro de la moda llamado Osberg ${ }^{46}{ }^{46}$ Así, unas páginas más adelante (hay que decir que la novela carece de capítulos y de toda subdivisión más allá de los espacios en blanco que separan los bloques de texto, que pueden variar desde una línea a varias páginas) encontramos una suerte de reescritura «taquigráfica », en clave de erudición denegante, del «Pierre Menard » de Borges, cuya famosa lista de "obras visibles » se ve aquí transfigurada en una lista de datos biográficos de un autor innominado del que sólo se dan las iniciales: RLV. Autor que podría ser histórico o imaginario, ${ }^{47}$ pero que en cualquier caso y a diferencia del Pierre 
Menard borgiano se propone como un boceto o apunte esquemático -una «silueta » que no llega a hacer visible una figura. ${ }^{48}$ Más bien, esta semblanza taquigráfica se lee como una suerte de reducción al absurdo del género biográfico (así como del juego textual de desciframiento de enigmas y acertijos) -una biografía dadaísta o "infraleve», para ponerlo en los términos duchampianos evocados por el propio Chitarroni en otro lugar ${ }^{49}$ :

RLV

¿Qué es lo que sabemos de su autor, después de leer Las patrias?

1) Que nació el 15 de diciembre de 1858.

2) Que no murió a pesar de un accidente y un atentado.

3) Que es de ascendencia irlandesa, portuguesa, española y judía.

4) Que, enamorado de mujer casada <a quien no menciona $>$ y amenazado de muerte,

tuvo <debió> /que/ regresar -o exiliarse- en Montevideo en 1878.

5) Que nunca $<$ no $>$ tuvo necesidad de trabajar.

6) Que empezó a escribir Las patrias en $1914<$ <1904?>.

7) Que su padre era amigo de Juan Crisóstomo Lafinur.

8) Que él conoció en diversas ciudades a Paul Groussac, Emilio Becher, W. H. Hudson, Hilario Ascasubi, Euclides da Cunha, Ireneo Funes, Alma-Tadema, el Príncipe de Faucigny-Lucinge, el Doctor Parkinson <iSinclair?>, Foucauld.

9) Que escribió además un drama en alejandrinos, La calumnia, y una pieza teatral en tres actos en francés (Une petite gare desafectée) <al revés, dice Eiralis>.50

El juego de oscilaciones y equívocos entre lo histórico y lo ficticio que cultivan éste y otros pasajes de Peripecias del no remite al trabajo borgiano con los apócrifos ${ }^{51}$, y puede relacionarse con la práctica del género biográfico que proponen sus Siluetas, que a su vez se inscribe en el subgénero de las biografías apócrifas o excéntricas: una larga tradición que iría de Marcel Schwob, Paul Valéry, Rubén Darío y Alfonso Reyes, a Max Aub, Juan Rodolfo Wilcock, Roberto Bolaño o Enrique Vila-Matas, y en la que es central la figura de Borges, ingenioso cultivador de ese subgénero en relatos como « Pierre Menard, autor del Quijote » o "Examen de la obra de Herbert Quain » y, notoriamente, en los « ejercicios narrativos » de Historia universal de la infamia (1935). ${ }^{52}$ La exploración de la cualidad ficcional de las vidas excéntricas que encontramos tanto en Peripecias del no como en Siluetas, donde coexisten los relatos de vida de autores famosos con los de escritores inverosímilmente oscuros (pero por lo general históricos) así como con personajes ficticios, remite indudablemente al tipo de perplejidades y paradojas histórico-literarias que cultivan numerosos textos de Borges. El principio de las biografías imaginarias de Chitarroni -como en cierto modo el de la entera literatura de Borges-, podría sintetizarse en esta frase de John Cage, citada en Peripecias del no: "Now let life obscure the difference between art and life $»^{53}$-una frase por cierto extraída de otro falso diario, un ensayo publicado en 1966 en la revista Aspen con el título Diary: How to Improve the World (You Will Only Make Matters Worst). Principio que inspira una práctica de «ficción infraleve » que por cierto propone como paradigma «El Aleph» borgiano - esa culminación de lo microficcional y lo infraleve ", según lo describe en Ejercicio de incertidumbre. ${ }^{54}$

Ahora bien, se diría que si las excéntricas semblanzas biográficas de Siluetas están más próximas al modelo borgiano, las que de manera abrupta y fragmentaria proliferan en Peripecias del no se acercan más bien al paradigma neodadaísta de des-composición textual encarnado por el autor de la Lecture on Nothing (1959) y de 4'33" de silencio (1952). La puesta en juego de una poética de la denegación enlaza con una de las vetas centrales de la literatura y el arte modernos, en la que junto al neo-dadaísmo de Cage podríamos ubicar el arte « no retiniano » de Duchamp, los lienzos incoloros de Rauschenberg, el arte « inmaterial» de Ives Klein (el Catálogo de obras no realizadas, la Sinfonía monótona), la 
escritura «impedida» de Beckett ${ }^{55}$, la escritura "abstracta " y post-literaria de Ulises Carrión y los «grafismos » de Mirtha Dermisache ${ }^{56}$, y obras como El grafógrafo (1972) de Salvador Elizondo, El discurso vacío (1996) de Mario Levrero o los textos macedonianos que inician la tradición de la literatura «impedida » en Argentina: Papeles de Recienvenido (1929), Continuación de la Nada (1944) y el Museo de la Novela de la Eterna (1967). Por otra parte, esa poética de la negación coexiste en la "novela inconclusa » con intermitentes ejercicios de virtuosismo estilístico, patente en los notables pastiches narrativos que contiene: entre otros, varios fragmentos « a la manera de Sir Thomas Browne $»^{57}$; un « cuento a lo Henry James, tal vez no necesario ", que se abre con una oblicua réplica de la frase inicial de «El Aleph »-58; o el relato o borrador de relato «El culto de St. Mawr », una suerte de «precuela » de la nouvelle de D. H. Lawrence, St. Mawr (1925), que incluye una reproducción de la portada de la versión en castellano (crasamente titulada La mujer y la bestia)..$^{59}$ De modo que por momentos la "novela inconclusa» de Chitarroni da la impresión de ser una extraña destilación del Museo de la Novela macedoniano y « El Aleph» de Borges -dos textos por lo demás íntimamente relacionados, más allá de sus divergencias narrativas y estilísticas (o justamente por ellas). Es como si Peripecias del no fuera una secuela de la anti-novela macedoniana, pero escrita a la manera de Borges, toda vez que el diálogo de Chitarroni con el proyecto macedoniano de la " novela impedida » ${ }^{60}$ no incluye su reivindicación de un "escribir mal y pobre $"{ }^{61}$-antes al contrario, se diría que a menudo compite con el virtuosismo estilístico y la elegante dicción de la literatura de Borges, amén de emular su gusto por la parodia y los juegos intertextuales (especialmente conspicuos en " El Aleph », que entre otras cosas es posible leer como una reescritura de la Divina Comedia y del propio Museo de la Novela macedoniano).

Peripecias del no es entonces un texto que combina inestablemente un principio de "cleptolalia» con otro de "criptodermia "-o bien, inversamente, un principio de " cleptodermia » con otro de "criptolalia ", en los términos propuestos por el autor. ${ }^{62} \mathrm{Si}$ por un lado lo mueve un impulso de imitación y « robo» de otros textos («cleptolalia ») ${ }^{63}$ -lo que más allá del pastiche de estilos puntuales como los de Henry James ${ }^{64} \mathrm{o}$ D. H. Lawrence lo lleva a trabajar la cuestión de la intertextualidad tan cara a Borges y a producir específicas imitaciones de sus textos y de sus hábitos estilísticos-, por otro pone en juego una bizarra decantación hermética, un trovar clus o "decir oscuro" ( " criptolalia ») que lo aleja de las preferencias literarias de Borges (especialmente en sus textos de madurez). Si la operación decisiva en las biografías apócrifas o excéntricas de éste (y en general en el relato borgiano) es la revelación, la iluminación cegadora, en la escritura denegante de Peripecias del no lo serían el diferimiento neutro, la indefinida proliferación de oscuridades y fugaces vislumbres. De esta escritura podríamos decir, en suma, lo que el propio Chitarroni aprecia en una nota sobre las Prosas de dormida (2005) de Carmen Iriondo: «El sueño verdadero, sueño oscuro, en las antípodas de la revelación, nos despierta lejos, en las afueras » (2008: 47). O quizá, como en el verso de Dylan Thomas que retorna como un mantra en Peripecias del no, habría que volver a decir: «La oscuridad es un camino, y la luz un lugar $"{ }^{65}$. 


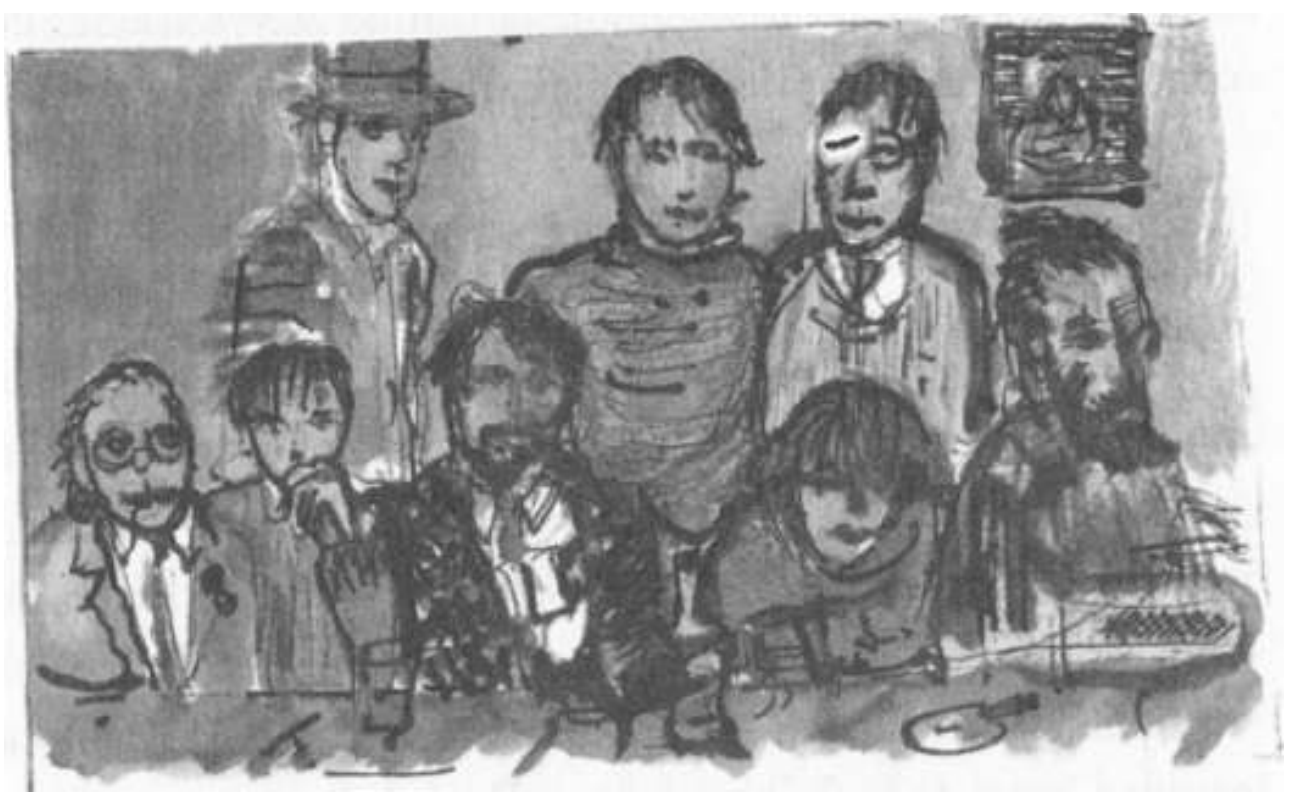

Fig. 1. « Retrato de grupo de Ágrafa ». Peripecias del no, p. 11.

\section{BIBLIOGRAPHY}

Aira, César. Taxol precedido de Duchamp en México y La broma. Buenos Aires: Simurg, 1997.

Beckett, Samuel. « Peintres de l'empêchement ». Disjecta: Miscellaneous Writings and a Dramatic Fragment. New York: Grove Press, 1983, p. 133-37.

Borges, Jorge Luis. « Pierre Menard, autor del Quijote ». Obras completas, Vol. 1. Buenos Aires: Emecé, 1989, p. 444-450.

--. « El Aleph ». Obras completas, Vol. 1. Buenos Aires: Emecé, 1989, p. 617-628.

--. Historia universal de la infamia. Obras completas, Vol. 1. Buenos Aires: Emecé, 1989, p. 289-345.

--. « Autobiographical Notes ». The New Yorker. New York, Sept. 19th, 1970, p. 40-99.

Cage, John. « Lecture on Nothing ». Silence: Lectures and Writings. Hanover, New Hampshire: Wesleyan University Press, 1973, p. 109-127.

--. Diary: How to Improve the World (You Will Only Make Matters Worse). Aspen, no 4, 1966, p. 1-13, disponible en: http://www.ubu.com/aspen/aspen4/diary.html, página consultada el 15/03/2017.

Calvino, Italo. Seis propuestas para el nuevo milenio. Madrid: Siruela, 2014.

Cohen, Marcelo. «La narración como inminencia del cierre. Conversación con Ricardo Piglia », Otra parte, $\mathrm{n}^{\mathrm{o}} 21$, primavera de 2010, disponible en: http://revistaotraparte.com/no-21primavera-2010/la-narración-como-inminencia-del-cierre, página consultada el 15/03/2017.

Chitarroni, Luis. Ejercicio de incertidumbre. La Plata: La Comuna Ediciones, 2008. 
--. Peripecias del no. Diario de una novela inconclusa. Buenos Aires: Interzona, 2007.

--. The No Variations. Diary of an Unfinished Novel. Trans. Darren Koolman. London: Dalkey Archive Press, 2013.

--. El carapálida. Buenos Aires: Tusquets, 1997.

--. Siluetas. Buenos Aires: La Bestia Equilátera, 2010 [1992].

--. « Temprano ». El nuevo relato argentino, ed. Héctor Libertella. Caracas: Monte Ávila, 1996, p. $127-148$.

Elizondo, Salvador. El grafógrafo. México: Joaquín Mortiz, 1972.

Fernández, Macedonio. Museo de la Novela de la Eterna. Ed. Ana Camblong y Adolfo de Obieta. Buenos Aires: ALLCA XX, 1996 [1967].

--. Papeles de Reciénvenido. Continuación de la Nada. Buenos Aires: Losada, 1944.

--. « Elena Bellamuerte ». Obras completas, Vol. 7. Buenos Aires: Corregidor, 1987, p. 99-102.

--. « Poema de trabajos de estudios de estéticas de la siesta ». Obras completas, Vol. 7. Buenos Aires: Corregidor, 1987, p. 133-136.

--. « El zapallo que se hizo cosmos ». Obras completas, Vol. 7. Buenos Aires: Corregidor, 1987, p. 51-54.

Gallix, Andrew. « The Novel without Qualities. An Interview with Luis Chitarroni », Gorse, Sept. 28, 2015, disponible en : http://gorse.ie/the-novel-without-qualities, página consultada el $15 / 03 / 2017$.

García, Francisca. « Leer lo no escrito: los grafismos de Mirtha Dermisache ». Poéticas del presente: perspectivas críticas sobre poesía hispánica contemporánea. Ed. Ottmar Ette y Julio Prieto. Madrid/ Frankfurt: Iberoamericana-Vervuert, 2017, p. 259-71.

Guebel, Daniel. La perla del emperador. Buenos Aires: Emecé, 1990.

--. El caso Voynich. Buenos Aires: Eterna Cadencia, 2009.

Iriondo, Carmen. Prosas de dormida. Buenos Aires: Sudamericana, 2005.

Laiseca, Alberto. La hija de Kheops. Buenos Aires: Tusquets, 1989.

Lamborghini, Osvaldo. El fiord. Buenos Aires: Chinatown, 1969.

Levrero, Mario. El discurso vacío. Buenos Aires: Mondadori, 2014 [1996].

Maderuelo, Javier. Ulises Carrión, escritor. Heras, Cantabria: Ediciones La Bahía, 2016.

Mallarmé, Stéphane. Un coup de dés jamais n'abolirá le hazard. Paris: Gallimard, 1914.

Montaldo, Graciela. « Un argumento contraborgiano en la literatura argentina de los años '80

(Sobre C. Aira, A. Laiseca y Copi) », Hispamérica, n 55, 1990, p. 105-112.

Perlongher, Néstor. Prosa plebeya. Ed. Christian Ferrer y Osvaldo Baigorria. Buenos Aires: Colihue, 1997.

Pound, Ezra. Personae: The Shorter Poems. New York: New Directions, 1990 [1926].

Prieto, Julio. La escritura errante: ilegibilidad y políticas del estilo en Latinoamérica, Madrid/Frankfurt: Iberoamericana-Vervuert, 2016.

--. De la sombrología: seis comienzos en busca de Macedonio Fernández. Madrid/Frankfurt: Iberoamericana-Vervuert, 2010. 
--. Desencuadernados: vanguardias ex-céntricas en el Río de la Plata. Rosario: Beatriz Viterbo, 2002.

Pron, Patricio. El libro tachado: prácticas de la negación y del silencio en la crisis de la literatura. Madrid: Turner, 2014.

--. No derrames tus lágrimas por nadie que viva en estas calles. Barcelona: Random House, 2016.

Quintín [Flavia de la Fuente, Flavia y Eduardo Antín]. « El libro más difícil del mundo / 1 », La lectora provisoria, 21 de junio de 2007, disponible en: https://

lalectoraprovisoria.wordpress.com/2007/06/21/el-libro-mas-dificil-del-mundo/, página consultada el 15/03/2017.

Rey, Pedro B. « El arte del desvío », La Nación. Suplemento Cultura, 24 de junio de 2007, disponible en: http://www.lanacion.com.ar/919712-el-arte-del-desvio, página consultada el 15/03/2017.

\section{NOTES}

1. Luis Chitarroni, Ejercicio de incertidumbre, La Plata: La Comuna Ediciones, 2008, p. 62.

2. Ibidem, p. 62.

3. Luis Chitarroni, Peripecias del no. Diario de una novela inconclusa, Buenos Aires: Interzona, 2007, p. 44.

4. Luis Chitarroni, op. cit., p. 63.

5. Luis Chitarroni, op. cit., p. 45.

6. Graciela Montaldo, «Un argumento contraborgiano en la literatura argentina de los años '80 (Sobre C. Aira, A. Laiseca y Copi) », Hispamérica 55, 1990, p. 105-112.

7. Luis Chitarroni, op. cit., p. 62.

8. He examinado algunas ramificaciones de esa saga en mis ensayos Desencuadernados (2002) y De la sombrología (2010), y más recientemente en La escritura errante (2016). Ver Bibliografía.

9. Luis Chitarroni, op. cit., p. 62.

10. Luis Chitarroni, op. cit., p. 7.

11. Como lo sugiere en una de las numerosas reflexiones metatextuales de la novela, "no hay núcleo narrativo en estos relatos breves, hay un destello informativo, referencial o alusivo, sólo eso. Y es que no se trata de una novela fácil ». (op. cit., p. 200 [bastardillas en el original]).

12. Jorge Luis Borges, "Pierre Menard, autor del Quijote », Obras completas, vol. 1, Buenos Aires: Emecé, 1989, p. 450.

13. A algunos de ellos se los menciona explícitamente un poco más adelante como participantes en una reunión donde leen y comentan lo que Chitarroni describe como su « primer cuento »-el relato "Temprano", publicado «en una antología que hizo Libertella para Monte Ávila en Venezuela» y reescrito intermitentemente a lo largo de la novela con el título «Demasiado tarde »-: « La reunión fue en el departamento de Charlie de la calle Independencia (el de El mal menor). Charlie, Alan, Chejfec, Guebel, Bizzio, yo » (op. cit. p. 13). Casi de inmediato el nombre de Chejfec es objeto de un humorístico détournement, por el que se torna ficticia «moneda de intercambio » en una supuesta novela del autor (de la que no hay otra constancia que este pasaje, a diferencia de las otras mencionadas): "En Trichinópoli, la novela que yo jugaba a escribir mientras los otros hacían lo mismo en serio, la moneda de intercambio era el 'chejfec' (derivado de check feckless coin) » (2007: 14).

14. El poema aparece incluido en su colección Personae (1926).

15. Esta interpretación no acaba de concordar con la « cronología de Ágrafa » que aparece en la segunda página de la novela (1958-1999), o con la ligeramente distinta que se propone hacia el final: « Ágrafa empezó a publicarse a fines de los cincuenta. Duró hasta mediados de la década del noventa " (op.cit., p. 171). La última etapa de Ágrafa vendría a coincidir con el periodo de 
publicación de Babel (1988-1991) pero su inicio sería bastante anterior al de Literal (1973-1977). En cualquier caso, lo interesante en la lectura de Rey sería la continuidad que sugiere entre las poéticas anti-narrativas de Literal (Osvaldo Lamborghini, Germán García, el primer Luis Gusmán) y las de los escritores nucleados en torno a Babel -el grupo Shanghai al que se adscribe Chitarroni. Tanto a unos como a otros les convendría en cierto modo el apelativo de « escritores sin historias » que se atribuye a los autores vinculados a Ágrafa/Alusiva: « se llamaban a sí mismos -y los llamaban- 'los escritores sin historias'. Iban por ahí publicando libros sobre teorías sobre que es mejor escribir sin contar historias que escribiéndolas, y para justificarlo contaban una » ( op. cit., p. 32).

16. Como se observa algo más adelante, «mito y biografía no dejan de entrecruzarse con frecuencia penosa en la historia de Ágrafa/Alusiva» (op. cit., p. 172). Esa continua oscilación entre lo (semi)ficcional y lo (semi)histórico es patente en el retrato de grupo de la revista que se incluye en la página 11 (ver figura 1). El continuo cruce entre lo histórico y lo ficticio deviene en cierto modo visible en el proceso de «desfiguración» que implica la transformación de la fotografía en acuarela, la cual se describe como un caso de "expresionismo malogrado » cuyo improbable autor (el hermano de «Remo Scacchi», a todas luces otro trasunto autorial) «la empezó con esmero y terminó desfigurándola con las imprecisiones de trazo grueso que lo caracterizaban » (op. cit., p. 11-12).

17. Entre otros: Felipe Luini, presentado como "discípulo de Leonardo", adalid de la "opacidad» (op.cit., p.10) y autor de una "serie de cuentos atrabiliarios que parecen no terminar, o que firmemente no terminan (porque, según el autor, hay una unidad secreta que convierte el repertorio en novela)» (op. cit., p. 235) ; Nicasio Urlihrt, « representante indiscutible de los grandes oscuros de la literatura » (op. cit., p. 241) ; Hilarión Curtis Ertebehere, « abuelo » de Nicasio Urlihrt, «el colaborador más asiduo y el fantasma de Canterville de Ágrafa » (op. cit., p. 233) ; Cristóbal Niaras, autor del ensayo "Ágrafa: laboratorio de azar» (op. cit., p. 218) ; Remo Sabatani, duchampianamente entregado a la creación de «su 'demora en tinta', un prodigio de arrogancia e inanidad ", así como autor de las obras Cuaderno en extinción, Novela con tres finales y siete comienzos y Las equis distantes -todas las cuales podrían ser títulos alternativos de Peripecias del no- (op. cit., p. 238); y aun Francisco Xavier Aldecoa Inauda, supuesto « poeta del Siglo de Oro » y profeta del hermetismo literario, que en una carta al escritor barroco Saavedra Fajardo declara (predicando con el ejemplo): "Vengo a deciros que es mejor en este mundo que permanezcan oscuros y desorientados porque, en beneficio de la jauría, el resplandor de la vida y la vigilia de ellos no pueden ni deben encontrarse » (op. cit., p. 193-94).

18. El propio Chitarroni al toparse por primera vez con el nombre «Gerhardie » lo juzga un invento, al considerar muy sospechosa esa -e final (común a tantos grandes autores: Dante, Shakespeare, Racine, Goethe...), lo que lo lleva a sopesar la posibilidad de adoptar en lo sucesivo el nom de plume «Chitarronie ». Ver Luis Chitarroni, Siluetas, Buenos Aires: La Bestia Equilátera, 2010, p. 144.

19. Andrew Gallix, «The Novel without Qualities. An Interview with Luis Chitarroni », Gorse, Sept. 28,2015 , n. p.

20. Quintín [Flavia de la Fuente y Eduardo Antín], «El libro más difícil del mundo », La lectora provisoria, 21 de junio de 2007, disponible en: https:// lalectoraprovisoria.wordpress.com/2007/06/21/el-libro-mas-dificil-del-mundo/

21. Luis Chitarroni, op. cit., p. 146.

22. Jorge Luis Borges, « El Aleph », Obras completas, vol. 1, Buenos Aires: Emecé, 1989, p. 623-24.

23. Luis Chitarroni, op. cit., p. 147.

24. Jorge Luis Borges, op.cit., p. 627.

25. Luis Chitarroni, op. cit., p. 147.

26. Luis Chitarroni, Ibidem, , p. 143. 
27. Afirmaciones en ese sentido abundan en su obra tardía ; véase por ejemplo Jorge Luis Borges, "Autobiographical Notes », The New Yorker, Sept. 19th, 1970, p. 86.

28. Luis Chitarroni, op. cit., p. 9.

29. De hecho la forma de «diario " no pasa de ser una vaga coartada para lo que más bien se presenta como heterogéneo cuaderno de apuntes, fragmentos y borradores. El único vestigio de escritura diarística es el fragmento titulado "Diario de Xochimilco », una secuencia de veinte páginas que narra el viaje a México de algunos de los miembros de Ágrafa, donde la premisa de la notación cronológica tiende por lo demás a reducirse al absurdo: las entradas del diario cubren aproximadamente tres horas de un único día (el domingo 21 de marzo, desde las 11 horas hasta las 14.48), de modo que en lugar de registrar el paso de una jornada a otra las entradas se suceden con intervalos de pocos minutos -una débil ilusión cronológica que además se ve desestabilizada por notaciones inescrutables o extemporáneas como «11.(20, ver siguiente) »o «11.(23, números primos)» (op. cit., p. 135).

30. Véanse por ejemplo las hilarantes variaciones de ese motivo en La hija de Kheops (1989) del recientemente fallecido Alberto Laiseca.

31. Luis Chitarroni, op. cit., p. 216.

32. La cualidad crepuscular, el «venir después» de esta constelación contraborgiana, se hacen explícitos en las frecuentes alusiones de Chitarroni a lo «tardío » de su escritura, lo que incluso se reivindica provocadoramente como una ventaja artística. Así, en el mencionado relato «Temprano », incluido en la antología El nuevo relato argentino (1994) compilada por Héctor Libertella y aquí significativamente rebautizado como «Demasiado tarde», afirma: «El arte es terminal: empieza cuando no hay más posibilidades» (op. cit., p. 148). Lo que concuerda con la declaración que se le atribuye en Peripecias del no a Enzo Nicosi -otro ficticio trasunto autorial-: «La literatura latina fue la primera importante sólo porque la precede la griega » (op. cit., p. 85).

33. El neobarroco latinoamericano tendría, de acuerdo con Néstor Perlongher, dos polos extremos: el «tatuaje » de Sarduy y el «tajo » de Lamborghini. Ver Néstor Perlongher, Prosa plebeya, Buenos Aires: Colihue, 1997, p. 135.

34. Luis Chitarroni, op. cit., p. 96.

35. Véase Stéphane Mallarmé, Un coup de dés jamais n'abolirá le hazard, Paris: Gallimard, 1914, p. 2.

36. «La literatura no se hace por acumulaciones sintácticas, por cúmulos gramaticales represivos, se hace haciéndose, música a la deriva » (op. cit. p. 200-201). La dimensión « musical » de esta anti-novela es también sugerida por el título de la traducción inglesa, The No Variations.

37. Luis Chitarroni, op. cit., p. 201.

38. Andrew Gallix, «The Novel without Qualities. An Interview with Luis Chitarroni », Gorse, Sept. 28, 2015, disponible en: http://gorse.ie/the-novel-without-qualities

39. Luis Chitarroni, op. cit., p. 205.

40. Como lo deja entrever el título de una de las obras de su «colaborador » Remo Sabatani -Las equis distantes-, la figura central en este texto es la incógnita no despejada -la X en cuanto emblema del cruce y en cuanto signo algebraico, como en la cita de Thomas Browne: «Letter $x$, (that) is the Emphaticall decussation, or fundamentall figure » (op.cit., p. 43). En consecuencia, se propone que « el mejor lugar para guardar un secreto es una novela inconclusa » (op. cit., p. 42).

41. Luis Chitarroni, op. cit., p. 222.

42. Luis Chitarroni, Ibidem, p. 72.

43. La pérdida o borramiento del sentido de la «inminencia de un final » intensifica la cualidad poética de este texto en la misma medida en que erosiona su narratividad, si consideramos que lo que define a ésta, según propone Ricardo Piglia, es una específica " práctica de la inminencia y del cierre »: « La experiencia tiene siempre algo inesperado y el final alude a la experiencia. En un relato el final decide el sentido, es un límite donde la separación entre literatura y experiencia está en cuestión. Lo que llamamos el final remite a una forma, pero la forma entendida como un marco, una frontera, un lugar de cruce. [...] Hay una idea de espera, algo está por ocurrir, mínimo 
quizá, pero inminente. Entonces la narración, en un punto, sería una práctica de la inminencia y del cierre" (Marcelo Cohen, «La narración como inminencia del cierre. Conversación con Ricardo Piglia », Otra parte 21, primavera de 2010, disponible en: http://revistaotraparte.com/n \% C2 \%BA-21-primavera-2010/la-narraci \%C3 \%B3n-como-inminencia-del-cierre).

44. Luis Chitarroni, op. cit., p. 194.

45. Pienso en textos como Duchamp en México (1997), del primero, o El caso Voynich (2009), del segundo -libro que se abre con dos epígrafes: una dedicatoria a Chitarroni y una «cita " en la ilegible lengua del manuscrito del siglo XVI que le da título.

46. Luis Chitarroni, op. cit., p. 186.

47. A partir de las iniciales podría ser tal vez un trasunto del poeta modernista mexicano Ramón López Velarde, cuyo poema más famoso es « La suave patria » (1921), aunque casi ninguno de los otros datos encajan -empezando por la fecha de nacimiento: López Velarde nace en 1888, treinta años después de la fecha de nacimiento que se atribuye a « RLV ».

48. La cualidad de borrador se manifiesta a lo largo del texto en el uso de corchetes angulares para incluir variantes de redacción alternativas (o aún no descartadas), lo que contribuye a ralentizar y dificultar la lectura. Esa cualidad es por lo demás inherente al proyecto de la « novela inconclusa ", como no deja de explicitarse: "Y sigamos aspirando -como Duchamp, como Leonardo- al borrador, al borrador definitivo» (op. cit., p. 178). La cualidad de borrador -en el sentido de una "definitiva inconclusión »- no implica sin embargo una « espontaneidad" o un descuido estilístico: antes bien, forma parte del diseño profundo de la obra y se manifiesta en una prosa cuidadosamente calculada en su tentatividad, como lo advierte otro pasaje: «Que de algo sirvan estas palabras: no estaba tratando de escribir algo experimental (y muchísimo menos espontáneo) cuando escribí este cuaderno. Estaba tratando de encontrarle una estructura ordenada a una cantidad intermitente <e incesante ipudor, pudor!> de ideas narrativas/ rotativas » (op. cit., p. 51).

49. En una de las notas de Ejercicio de incertidumbre reivindica la práctica de una "ficción infraleve », noción que vincula con las categorías de « microficción » y « camuflaje »: « A menudo el gusto de un escritor de ficciones infraleves consiste en disimularlas en el follaje propicio de una narración que ayuda a ensayar este camouflaje < $i$ ?>. [. . .] En gran medida, la microficción y la ficción infraleve -o 'cuento oculto'- comparten también una condición de angustia y codicia: pretenden abolir el mundo -o al menos esa superficie de mundo llamada realidad- en unos pocos renglones » (op. cit., p. 67-68).

50. Luis Chitarroni, op. cit., p. 84.

51. Ese juego incluye en un mismo plano a figuras históricas como los autores Paul Groussac, W. H. Hudson, Hilario Ascasubi o Euclides da Cunha junto a personajes ficticios como Ireneo Funes (el protagonista del relato de Borges « Funes el memorioso ») y a otros de existencia dudosa más allá del juego lingüístico (como «Foucauld») o de condición histórica pero vagamente contaminada de irrealidad, como Juan Crisóstomo Lafinur, pariente lejano de Borges cuya historicidad es en cierto modo indisociable de las esporádicas menciones de su nombre en la obra literaria de su sobrino bisnieto.

52. Sobre esta tradición véase el capítulo «Falsificadores» de El libro tachado (2014) de Patricio Pron, cuya última novela, No derrames tus lágrimas por nadie que viva en estas calles (2016), bien podría incluirse en el subgénero de las biografías imaginarias.

53. Luis Chitarroni, op. cit., p. 14.

54. Luis Chitarroni, op. cit., p. 69.

55. Parafraseando lo que observara Beckett en su ensayo sobre los « Pintores del impedimento » (1948) - «st peint ce qui êmpeche de peindre», noción fácilmente extrapolable a su propia escritura-, se diría que en la práctica denegante de Chitarroni, "se escribe lo que impide escribir ». (Ver Samuel Beckett, « Peintres de l'empêchement », Disjecta: Miscellaneous Writings and a Dramatic Fragment, New York: Grove Press, 1983, p. 136.) No en vano el leitmotiv de su «novela 
inconclusa » es la palabra NO escrita en mayúsculas (o, alternativamente, la expresión « NO se puede ») insertada aleatoriamente a lo largo del texto y al final de numerosos fragmentos, como si se tratara de versiones descartadas o "tomas falsas » de un filme aún por montar o a medio hacer (pero que de hecho no aspira a ser otra cosa que un cierto sistema de descartes y tomas falsas).

56. Sobre Carrión y Dermisache véanse los trabajos de Javier Maderuelo y Francisca García incluidos en la Bibliografía.

57. Luis Chitarroni, op. cit., p. 90.

58. Luis Chitarroni, op. cit., p. 50-51 [bastardillas en el original].

59. Luis Chitarroni, op. cit., p. 114.

60. Entre los vínculos macedonianos que propone la «novela inconclusa » de Chitarroni, cabe destacar el nombre de la revista Ágrafa, que aparte de contener un chiste sobre la condición « no escrita » (en tanto que apócrifa) de la revista, remite al mito de Macedonio como genio socrático construido por Borges (aunque más exacto sería hablar de una crítica de la institución artísticoliteraria desarrollada a través de una incesante práctica grafómana), así como también podría relacionarse con las peripecias «no-escriturales » de su personaje autorial Recienvenido y con las tácticas de diferimiento de la escritura que despliega en sus brindis, discursos y colaboraciones en la Revista oral (1925-26) -otro posible antecedente histórico de la revista Ágrafa. Igualmente significativo es el nombre de una de las fundadoras de la revista, que además se presenta como la mujer del alter ego autorial Nicasio Urlihrt (anagrama de Luis Chitarroni): «Elena Siesta ", nombre que condensa la alusión a dos obras seminales de Macedonio: el poema «Elena Bellamuerte " (dedicado a su mujer Elena de Obieta, fallecida en 1920) y el ensayo "Poema de trabajos de estudios de estéticas de la siesta » (1940).

61. Macedonio Fernández, «El zapallo que se hizo cosmos », Obras completas, vol. 7, Buenos Aires: Corregidor, 1987, p. 54.

62. «Cleptolalia/criptodermia // y viceversa: cleptodermia/criptolalia » (op. cit., p. 12).

63. «Que de otro imitó los modos / por conocerlos a todos » (op. cit., p. 8) -tal sería el lema de esa práctica de «cleptolalia » propuesta ya desde la segunda página de la novela, en un pasaje donde a la vez introduce un principio de «criptodermia » en el juego de la nominación insidiosa y en el ocultamiento de la cita, vinculada a un improbable poeta del Siglo de Oro -" Aldecoa Inauda », un " antepasado» de su alter ego Nicasio Urlihrt. Hacia el final de la novela la cita se atribuye al poeta culterano Gabriel Bocángel (1603-1658), que habría dedicado ese dístico a Inauda, en un fragmento que interesantemente contrapone la tradición renacentista y manierista de la imitatio a la «cleptolalia» de los escritores contemporáneos de Ágrafa: «Pero él [Inauda] era de los favorecidos, de los dotados. Nosotros, en cambio, los tortuosos, copiábamos e imitábamos sin conciencia, como si lleváramos el plagio incorporado en un transistor, en un chip dicen ahora » ( op. cit., p. 214).

64. « NO se puede. // NO suena ni lejanamente a James traducido» (op. cit., p. 58), observa en clave denegante al final de uno de esos fragmentarios pastiches, que se dan de manera entrecortada y con múltiples interrupciones y comentarios metatextuales, dejando en el aire su posible continuidad -a veces el relato se retoma mucho después de interrumpirse, extrañando o debilitando radicalmente la ilación narrativa ; otras, se abandona sin más.

65. Luis Chitarroni, op. cit., p. 187. 


\section{ABSTRACTS}

This essay explores the poetics of obscurity that informs Luis Chitarroni's " unfinished novel » The No Variations. Focusing on the "reticent » erudition that distinguishes this text, my analysis examines its dialogue with the paradigm of Borges' erudition and narrative poetics, as well as with certain « counter-Borgesian » constellations in recent Argentine literature. My reading aims to show how Chitarroni's anti-novel reactivates a specific Argentinean tradition of productive illegibility while considering how it relates to the practices of «impediment " and "aesthetic reduction » that pervade modern art and literature.

Este ensayo explora la poética de la opacidad en la escritura de Luis Chitarroni y en particular en su « novela inconclusa » Peripecias del no. El análisis se enfoca en la erudición " denegante » que distingue a este texto, y en su diálogo con el modelo de la erudición borgiana y con su poética narrativa, así como con una serie de líneas "contraborgianas" en la literatura argentina reciente. Mi lectura se orienta a mostrar cómo la anti-novela de Chitarroni reactiva una específica tradición literaria argentina de poéticas de lo ilegible a la vez que enlaza con las prácticas del « impedimento » y de la « reducción estética » que recorren la modernidad artística y literaria.

Cet article explore la poétique de la opacité mise en jeu par Luis Chitarroni dans son « roman inachevé » Aventures du Non. À partir d'une analyse de l'érudition "reticente » inhérente à ce texte, j'examine le dialogue que Chitarroni établit avec le modèle de l'érudition borgésienne et sa poétique du récit, ainsi qu'avec une série de lignes narratives "post-borgésiennes" dans la littérature argentine récente. Ma lecture vise à montrer comment l'« anti-roman » de Chitarroni réactive une particulière tradition littéraire argentine relative aux poétiques de l'illisible tout en se liant à la fois avec les pratiques de l'« empêchement » narratif et de la « réduction esthétique » qui traversent la modernité artistique et littéraire.

\section{INDEX}

Palabras claves: poéticas de lo ilegible, hermetismo, Chitarroni, Borges, arte moderno Keywords: poetics of the illegible, hermeticism, Chitarroni, Borges, modern art Mots-clés: poétique de l'illisible, hermétisme, Chitarroni, Borges, art modern

\section{AUTHOR}

\section{JULIO PRIETO}

Universität Potsdam

ju.prieto3@gmail 